\title{
METALLOSCOPY AND METALLOTHERAPY.
}

\author{
BY A. HUGHES BENNETT, M.D., \\ Phyotian to the Hoopital for Epilopry and Paralyria, Rogenf's Park, and \\ Assiotant-Phyviaian to the Westminstor Hospital.
}

THE treatment of disease by the external application of metals has been practised from the earliest ages. The ancients wore rings and amulets which, combined with supplications and sacrifices to the gods, performed marvellous cures. Paracelsus is reported to have placed metallic substances on the skin to relieve internal complaints, and Pomme, two centuries later, becrme celebrated for his treatment of nervous disorders by means of copper baths. The discovery during the eighteenth century of galvanism and electricity gave a fresh stimulus to researches on this subject, and the enthusiasm created by the knowledge of these powerful agents added a fresh impulse to the study of metallotherapy; galvanic and electric piles, batteries, and the application of simple metals were energetically employed as curative agents. Perkins, at the commencement of this century, used needles of different metals, which he thrust into the body with the view of establishing electric currents. Twenty years later, when electricity began to be applied scientifically to medicine, various methods of external treatment by metallio substances were employed. Among others Raspail used plates of zinc and copper, Goldberger introduced galvanic chains, Sage applied powders of copper and steel, Recamier suggested poultices of copper and zinc, Pulvermacher constructed chains of zinc and copper, and there arose a host of other contrivances for the purpose of influencing abnormal states by means of external metallic applications. 
M. Burq, in 1848, was the first to make a scientific investigation into, and to form any definite-system on, the external application of metals to the treatment of disease, and in a remarkable work, he describes his extensive observations and experiments on the subject. ${ }^{1}$ He ascertained that workers in copper were exempt from cholera during many of the severest epidemics of Paris, and he subsequently found that the external and internal administration of that metal relieved the symptoms of others when attacked with the disease in question. ${ }^{2} \mathrm{He}$ then maintained that chlorosis was cured by the extermal application of various metallic substances, which he accounts for by considering that affection not a disorder by itself, but only the symptom of a nervous disease over which this procedure has a beneficial influence. $^{3}$

He subsequently applied his system to a variety of other affections, but met with the greatest success in the treatment of hysteriz, the most troublesome symptoms of which were often relieved or cured.

Burq's method of procedure was first by means of small discs to ascertain the metal which had some influence on the patient, and then to envelop him in a sort of armour of the same substance. This cuirass was kept on for days, weeks, or months, until the beneficial changes were considered complete. The worke of $\mathbf{M}$. Burq during the last thirty years contain so many and remarkable cares by what seems so simple a process, that it is singular that the profession at large have apparently so little benefited by his instractions. Burqism, however, like Braidism, seems to be a doctrine which is more efficacious in the hands of its author than in those of others, and the results, if genuine, may possibly be due to the personal influence of an individual rather than to the exactness of a system. Hence both have hitherto been abandoned by the medical profession in the practical treatment of disease. They are closely related, Burq himself expressing great sympathy with mesmerism, and he admits that by means of metals he can

1 'Métallothérapie," pap 'Dr. V. Burq. Puris, 1853.

- 'Da Cuivre contre le Choléra,' par Dr. V. Burq. Parie, 1867.

- 'L'Etude de la traitement de la Chloroec,' par Dr. V. Burq. Parie, 1852. 
prognose those likely to be sensitive subjects in the operations of the Hypnotiser.

Professor Charcot, of Paris, has recently revived the system of Burq in the treatment of "Grave Hysteria," and in a recent number of the Lancet his views are expounded." His observations have since been apparently confirmed by Dr. Henry Thompson, ${ }^{2}$ Mr. Horrocks, ${ }^{3}$ in the wards of Dr. Wilks ' and others, both at home and abroad.

I have repeated aIl the experiments and observations of these anthorities in several cases of anesthesia and analgesia which have recently been under my care, and although brevity compels me to omit details, I venture to say a few words on the results obtained, and will use the writings of the above authors as a text for my remarks.

1. It is stated that in certain cases of anæsthesia and analgesia the application of various metals is followed by a return of sensibility to touch and pain. This I have ascertained to be a fact. 'In a case at present nnder observation, where there is complete hemianæsthesia, including the special senses of the right side, a limb treated after the process of Burq and Charcot is often entirely restored to its natural function. This restoration is usuelly temporary, but is sometimes permanent. Occesionally the effect extends over the whole body, but is more often confined to the limb or neighbourhood of the applied metal.

It is also asserted that each individual is influenced by one particular metal, while others fail to have a beneficial action. As far as my experience has gone it is not in accord with this statement : I have found, after repeated and extended trials, that it apparently makes little difference what substance is employed, the result being in all cases the same. For example, in one patient $\mathrm{J}$ tested a variety of metals without the slightest effect. Finally, on employing zinc, local sensibility was completely restored for some hours. Next day zinc was again used with similar results, and so on. Subsequently, on applying the metals which had formerly failed, the same phenomena ensued,

1 Lancet, January 19th, 1878.

- Britieh Medioal Jourmal, Norember 30th, 1877.

3 Guy's Hoopital Gasotto, A pril 1878.

- Britioh Medioal Jortnal, July 19th, 1878. 
and sometimes when zine was tested no change whatever took place. In short, in this case the application of metals usually induced changes in sensation, but there was no constancy as to the effects produced by any particular one of them; that which caused a return of sensibility yesterday did not to-day, and that which failed to-day might succeed to-morrow.

Finally, this question arose. Are the phenomena induced really due to any special virtue in the metal, as is alleged? To solve this problem I have applied dises of wood, and have produced thereby all the phenomena described as following the application of the metals. In a case at present in the Westminster Hospital, of a woman with complete hemianæsthesia and hemianalgesia from which she had suffered for upwards of a year, after testing a number of metals with varying success, I applied two wooden buttons to her arm. From complete insensibility to pain and touch in half an hour the arm was normal to both, and has remained so ever since, that is for the last three months, the other parts of the body continuing anæsthetic and analgesic as before. This observation with the wooden discs has been frequently repeated, and the results have been, in the writer's experience, as certain and constant as from any single metal.

2. It is stated that the muscular force, as messured by the dynamometer, is increased by the application of metals in anoesthetic cases. I have also found this statement in a certain degree to be correct. There can be no doubt that the arm and hand when sensitive to touch can exert a greater force than when they are anæsthetic. But whether due to any special metallic virtues is more than questionable, as the same results followed the treatment by wooden discs. In short, so far as my observations extend, I have found that a relation exists rather between the power and the sensation, from whatever cause modified, than between the power and the metal employed.

3. It is asserted that external metallic applications exert an influence on the circulation from the fact that when anæsthetic skin is pricked no blood flows from the punctures; but that after metals have been applied and the sensibility restored, this takes place. To a certain extent these observations are correct, 
and I have repeatedly confirmed them. I have seen frequently that a puncture of anæesthetic skin by a needle did not bleed, while fresh pricks after the skin bocame sensitive were followed by bleeding points. But I have never seen the same punctures which did not bleed at first afterwards do so when the metal was applied. That these changes are due to the action of the metals per se on the circulation is also doubtful, as the same phenomena followed the application of the wooden discs.

The following observation, made by myself, may hare some bearing on this subject. In a normal condition of the skin, if a needle be deliberately thrust through its thickness, taking care to avoid a vein, on withdrawal of the instrument no blood follows, as a rule. If, however, the skin be lightly pricked, small spots of blood issue from each puncture. If the same operations be made on anæsthetio skin, precisely similar phenomena ensue. In short, the nature of the wound inflicted by the needle seems alone to determine if blood shall follow, and this whether the skin be anesthetic or not. This may serve to explain the circulatory changes supposed to be produced by the metals. When skin is anæsthetic the operator is not particular, he thrusts the needle deeply, and no blood in consequence appears. When sensibility is restored he is obliged to be more careful, and gently touches with the point of his instrument the sensitive integument, and, as nearly always occurs, blood is seen at several points. After the use of the metals I have frequently observed redness of the skin, but have always considered that this was due to the previous pricking and pinching necessary to test its anæsthetic condition. It must, however, be admitted that it is highly probable that the return of sensibility to a part indicates a change in its capillary circulation, and that sensitive portions of the skin are more likely to be vascular than those which are anæsthetic.

4. The phenomenon called by Burq "l'anesthésio de retour," I have occasionally seen as described by Charcot, but by no means constantly. He says that when the metal has been applied to anesthetic skin, and semsibility restored, and if the treatment be continued, at a given moment the ano 
thesia returns more persistently than before. I have never observed this sudden change. In my experience, the sensibility having been restored, either by metals or discs of wood, it remains an hour or more, and then gradually is lost. In some cases the application having been maintained for twentyfour hours, the anmsthesia was as great as before; in others, however, the sensibility was markedly increased. Charcot then says, if the metels are removed at the moment sensibility is restored, the effects are often permanent, and spread over the remainder of the body. This I have found to take place; but on the other hand, the same circumstances existing, the anæsthesia has often returned in a very short time, and when it remained has been limited to the spot or limb originally restored. In the case before cited, at present under observation, the right arm from absolnte anæsthesia was restored to normal sensibility after the epplication of two discs of wood for an hour. The arm has remained in the same condition for three months, the rest of the body continuing anesthetic.

5. The "phenomène du transfert" discovered by Charcot, he describes as follows:-Having applied a metal to an anæsthetic arm, and restored sensibility to a portion of it, the exactly corresponding part of the other, and hitherto normal, limb is found to be anæsthetic, and as this latter returns to its normal condition the former resumes its previous state. I myself have never observed such an exact displacement of sensibility. It has been noticed that occasionally, when the skin on one side has been restored to feeling of touch and pain, the corresponding portion of the other side hes become less sensitive than before; but frequently no such phenomenon has taken place, one limb being changed, the other remaining in its usual condition.

6. The achromatopsy observed by Charcot, in which the patient loses the notion of colours in a certain mathematical regularity, and after the application of metals regains the knowledge of them in the same order, I have had no opportunity of definitely testing. In one case of hemianssthesia on admission the patient could not, with her right eye, distinguish any colours; all seemed alike grey, some appenring 
darker than others. A few days afterwards she said that blue was green, green was blue, light blue was grey, but failed even to attempt to name any others. A week subsequently she told all the colours correctly, and has done so ever since. This patient, up to that time, had received no treatment whatever.

7. Metalloscopy being the search for the metal which affecte the patient, metallotherapy consists in employing the same for the treatment of disease, either by administering a solution of it internally, or by applying plates of it externally. From the foregoing remarks it is obvious that I can have had little opportunity of testing this, as I have never yet found a patient who was affected by one particular metal, and by it alone. In a case in which discs of zinc removed the anæsthesia, valerianate of zinc was taken for a month without any apparent effect; and in another case of anresthesia of the leg, which was modified by the application of two pieces of wood, I, in joke, gave her frequent dram doses of infusion of quassia, and the patient declared herself well in a week. In a third case, where a small diso of zinc restored sensibility, a large plate of the same failed to do so the following day. Many remarkable cases, however, described by Barq, Charcot, Thompson, and others, may deserve consideration from the reputation of the observers.

In reviewing the whole question, one point may be admitted, namely, the genuine nature of these remarkable phenomena; and $I$ can personally grarantee that in my own observations every possible precaution was taken to detect malingering or unconscious deception, and to test the real accuracy of the results. The patients were all carefully blindfolded during the entire period of the experiment; not a word was spoken concerning the nature of the observation; no suggestive ideas were given, and no leading questions asked.

The practical problem to be solved appears to me to be this : Are the beneficial changes due to some special effect, electrical or otherwise, derived from a particular metal, or do they result from the influence its application exercises on the mind, which in its turn directly affects the body? Precisely the same question was asked some years ago when "electro-biology" 
startled the public mind by its marvellons revelations, and was conclusively answered by Braid and others. From the earliest ages, cures and miracles have been performed by very much similar processes, many of which were doubtless genuine, but time and scientific investigation have always proved them to be subjective phenomene. My own observations certainly seem to support this view of the question; at the same time, my experience is small, for cases of "grave hysteria" are rare in Anglo-Saxon England, as compared to France with her Latin and Celtic races. Even Charcot declines to give a decisive reply to this question, but contents himself by drawing the conclusion "that the question is deserving of careful attention." He very properly points out that in sach investigations one "should keep aloof as much as possible, both from the arbitrary scepticism which too often arises from pedantio ignorance, and from that naive credulonsness which characterises the charcosl-burner's faith. It is between these two reefs, which are equally dangerous, that the observer must know how to steer."

Without wishing to give a hasty or decisive opinion on the matter, or to deny that subsequently another explanation may prove satisfactory, it must be admitted the above observations tend to show that the beneficial changes resulting from the application of metals to the skin are due rather to the mental effects they prodace than to any special virtues emanating from the metals themselves. This is further supported by the following considerations:-

1st. These phenomena occur for the most part in women, and in persons of a hysterical temperament, who are proverbially prone to rapid and sudden changes readily induced by emotion or expectant attention.

2nd. None of the effects resulting from the application of metals are inconsistent with what is well recognised as the influence the mind possesses over the body.

3rd. The symptoms of anæsthesia and analgesia are so changeable and unstable as to render it difficult to say positively when they are directly affected by remedies. I have, for example, at present under my care in the mards of the Westminster Hospital a girl who frequently for hours 
together has complete anæsthesia and analgesia of the right thigh. At other times her skin is perfectly normal, and this without any treatment or apparent cause. We have also no accurate physical means of measuring sensibility, and nre for the most part dependent on the statement of the patient.

4th. The facts that $(a)$ the action of the metals has been in the hands of the writer uncertain and inconstant, many of these inducing similar effects at different times, and any particular one causing diverse actions on separate occasions; (b) that no metal is apparently specially suitable for any given patient, for that which feils at one time may succeed at another; and (c) that no metal at all is required, discs of wood having produced all the alleged phenomena-would seem to indicate that the effects of metallotherapy are of mental and not of physical origin; and that, however highly endorsed, we should pause before accepting too readily a theory which appears to be only a revival of a long-exploded doctrine. 